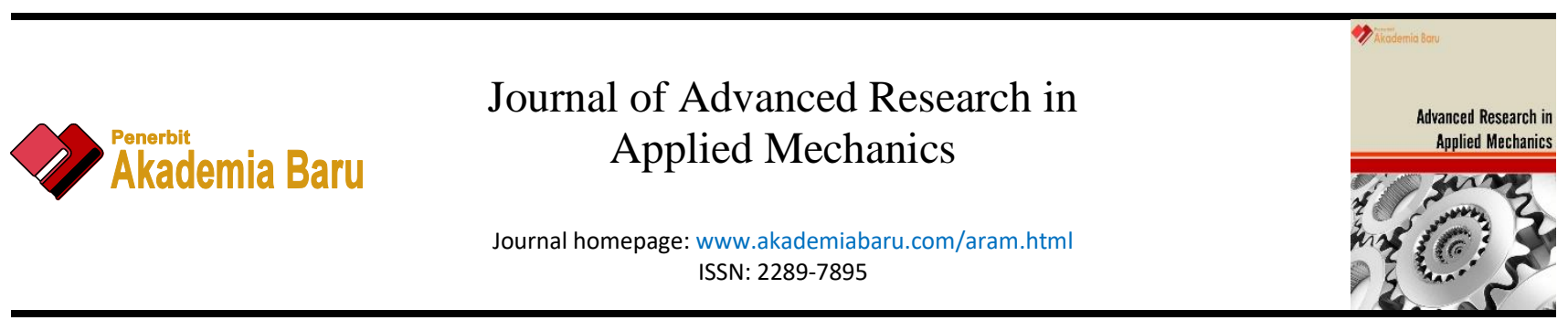

\title{
The Effects of Sterilization Time of FFB on Fruit-Bunch Separation and Crude Palm Oil Quality Using Direct Steaming
}

\author{
Siravit Pakdeechot ${ }^{1}$, Sherly Hanifarianty ${ }^{2}$, Makatar Wae-hayee ${ }^{1, *}$ \\ Department of Mechanical Engineering, Faculty of Engineering, Prince of Songkla University, 90112 Hat Yai, Songkhla, Thailand \\ 2 Sembawa Research Center, Indonesian Rubber Research Institute (IRRI), Jalan Raya Palembang-Pangkalan Balai KM. 29, P.O. BOX 1127, \\ Palembang, South Sumatera, 30001, Indonesia
}

\section{ABSTRACT}

In palm oil milling factory, Fresh Fruit Bunch (FFB) must be undergone by sterilizing before processing oil extraction. In commercial industry, conventional sterilization units, a boiler and a sterilizer in steaming process, are separated. This is affected on heat losses and produced a lot of waste water. To minimize heat losses and producing waste water, a boiler and a sterilizer can be combined in one unit. Therefore, the aim of this work is to study ability to combine the boiler and the sterilizer in the same unit. A palm fruit bunch was sterilized in mini sterilizer by direct steaming at 1.5 bar for 30, 45 and 60 minutes. The results show that a percentage of fruit-bunch separation and crude palm oil yield increased when sterilization time was longer. The trend of increasing crude palm oil yield is similar to the trend of increasing fruit-bunch separation. Sterilization time up to 45 minutes, the fruit-bunch separation and CPO yield was approximately $90.36 \%$ and $26.72 \%$, respectively, and Free Fatty Acid (FFA) was not more than $1.25 \%$. This direct steaming method is possible to apply in sterilization process of oil palm bunch. It could decrease energy consumption and waste water.

\section{Keywords:}

Fresh Fruit Bunch (FFB), Palm Oil Milling,

Crude Palm Oil (CPO), Oil palm

sterilization, Steaming

Copyright @ 2020 PENERBIT AKADEMIA BARU - All rights reserved

\section{Introduction}

Oil palm is commercial plantation which produce widely in Indonesia, Malaysia and Thailand. Based on a comparison of plantation area, an oil yield of oil palm is the largest as compared to a yield of other oily fruits. Palm oil fruit comprises 22.1 percent of oil yield when fully mature (Table 1). The Maturity index of palm oil fruit can affect the oil yield and free fatty acid (FFA). Processing palm oil fruit without delay could produce 87 percent of oil extraction and a good quality FFA reaching 2.31 percent [1]. FFA intended for commercial purposes should not exceed 5 percent [2]. Therefore, it is important to process palm oil fruit immediately after harvesting $[3,4]$. The FFA percentage could increase due to a long storage period which results in damaged fruit [5-8] while high FFA in vegetable oil generally indicates the poor process that causes the breakdown of triglyceride after refining [9].

\footnotetext{
* Corresponding author.

E-mail address: wmakatar@eng.psu.ac.th
}

https://doi.org/10.37934/aram.72.1.19 
Table 1

Oil yield and FFA for each maturity level of oil palm [10].

\begin{tabular}{lll}
\hline Fruit maturity & Oil yield, $\%$ & FFA, \% \\
\hline Immature fruit & 16 & 1.6 \\
Half-mature fruit & 21.4 & 1.7 \\
Mature fruit & 22.1 & $1.8-2.1$ \\
Over-mature fruit & 21.9 & $2.6-3.8$ \\
\hline
\end{tabular}

After harvesting fresh fruit bunches (FFB), the bunches need to be delivered to a milling factory immediately or not more than 24 hours. The bunches are undergoing sterilizing to minimize low quality oil palm from increasing FFA. Therefore, sterilization plays an important role in palm oil milling processing $[11,12]$. The Sterilization process uses steam with pressure at $40 \mathrm{psi}\left(140^{\circ} \mathrm{C}\right)$ for $75-90$ minutes $[13,14]$. The purposes of sterilization include softening the bunch, facilitating the fruit release from the bunch, enzyme inactivation, reducing the water content in the fruit and facilitating oil extraction [15-18].

During the sterilization process, the moisture is influenced by steam which chemically breaks down resin and starch causing oil to foam. Poor sterilization might be caused by secondary oxidation that leads to discoloration of palm kernel and deterioration of bleaching index (DOBI). Hadi et al. [19] studied a sterilization process of FFB in a mini sterilizer operating at a pressure of 2.6 bar and saturation steam temperature at $140^{\circ} \mathrm{C}$ with different sterilization time for $40,50,60$ and 70 minutes. The study focuses on a total number of loose fruits which were detached from the bunch after sterilization process and the percentage of total loose fruits per the estimated total fruits for one bunch. The results suggest that total stripping of loose fruits from the stalk after sterilizing manual hand threshing procedure from the bunch occurs at sterilization time 70 minutes, whereas at 60 minutes the percentage of loose fruits obtained is close to $90 \%$ the estimated percentage detached loose fruit obtained at 60 minutes which is $90 \%$ is considered to be adequate as the minimum amount of loose fruit remaining in the bunch to be considered as empty bunch is $10 \%$ [20]. Sukaribin and Khalid [21] studied an effectiveness of sterilization of oil palm bunch using microwave heating. A power of microwave heating was varied at 1, 1.5 and $2 \mathrm{~kW}$. They explained that show that the heating of microwave is required to achieve better stripping efficiency and the sterilization can be done at shorter time by increasing the microwave power level. Umudee et al. [22] reported that drying oil palm by using microwave at $50-80^{\circ} \mathrm{C}$ which is the optimum temperature range for heating oil palm. In commercial industry, there are several sterilization types using steaming such as horizontal sterilizer [23], vertical sterilizer [23] and continuous sterilizer [23-26].

A palm oil milling factory requires a large amount of energy consumption during the processing. The sterilization process is the highest energy consumption as compared to other processes, especially, producing steam in boiler. As aforementioned steaming sterilization types, the boiler and the sterilizer is separated in each unit. This is affected in term of heat losses in steaming, piping and sterilizing processes. To minimize these heat losses, a boiler and sterilizer can be combined in one unit. Therefore, this work focuses on ability to combine the boiler and sterilizer in the same unit.

The aim of this work is to investigate sterilization of palm fruit bunch by direct steaming in mini sterilizer which was combined the boiler and sterilizer in the same unit. The effect of sterilization time on fruit-bunch separation and crude palm oil quality. 


\section{Methodology}

\subsection{Experimental apparatus}

The schematic diagram of FFB sterilization using in this work is shown in Figure 1 . The mini sterilizer of FFB by direct steaming was made of metal sheet with an inner diameter of $35 \mathrm{~cm}$, a height of $60 \mathrm{~cm}$ and a volume of 58 liters. A fiber glass insulator was covered the sterilizer externally for minimizing heat losses to environment. A grille was assembled internally at the bottom for separating boiling water and FFB with a height of $2 \mathrm{~cm}$ from the base. A pressure gauge and pressure relief valve for controlling pressure in the sterilizer were assembled at the sterilizer cover. The pressure was constant at 1.5 bar \pm 0.2 bar while sterilization time was varied at 30,45 and 60 min, including initial heating. A T-type thermocouple for measuring steam temperature were located the center of sterilizer. LPG was used as fuel for boiling water by burning at the bottom of sterilizer. A rotameter was used to control LPG flow rate. In this study, FFBs were selected 3 bunches for every condition with similar size, weight and ripeness.

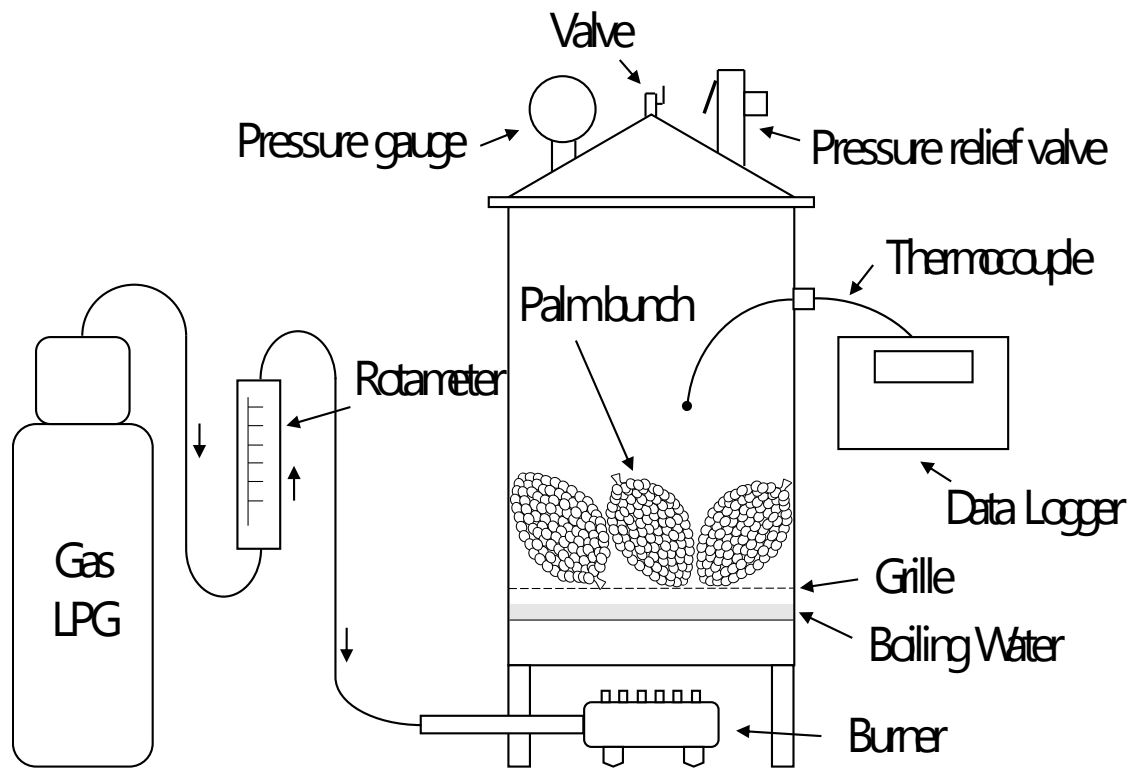

Fig. 1. Palm fruit bunch sterilizer by direct steaming device

\subsection{Palm fruit bunch separation}

A schematic diagram of bunch-fruit separator was shown in Figure 2. Pins with $7 \mathrm{~cm}$ length were assembled in internal surface of $96-\mathrm{cm}$-diameter cylindrical metal and rotating disk. The rotating disk was rotated by 7.5-HP electric motor associated with gear box with constant rotation speed of 70 $\mathrm{rpm}$. The bunch was crashed lateral pins by centrifugal force of rotation disk. The FFBs after sterilizing was loaded suddenly into the bunch-fruit separator. To evaluate a percentage of bunch-fruit separation, the operating time of every case was fixed at $1 \mathrm{~min}$. 


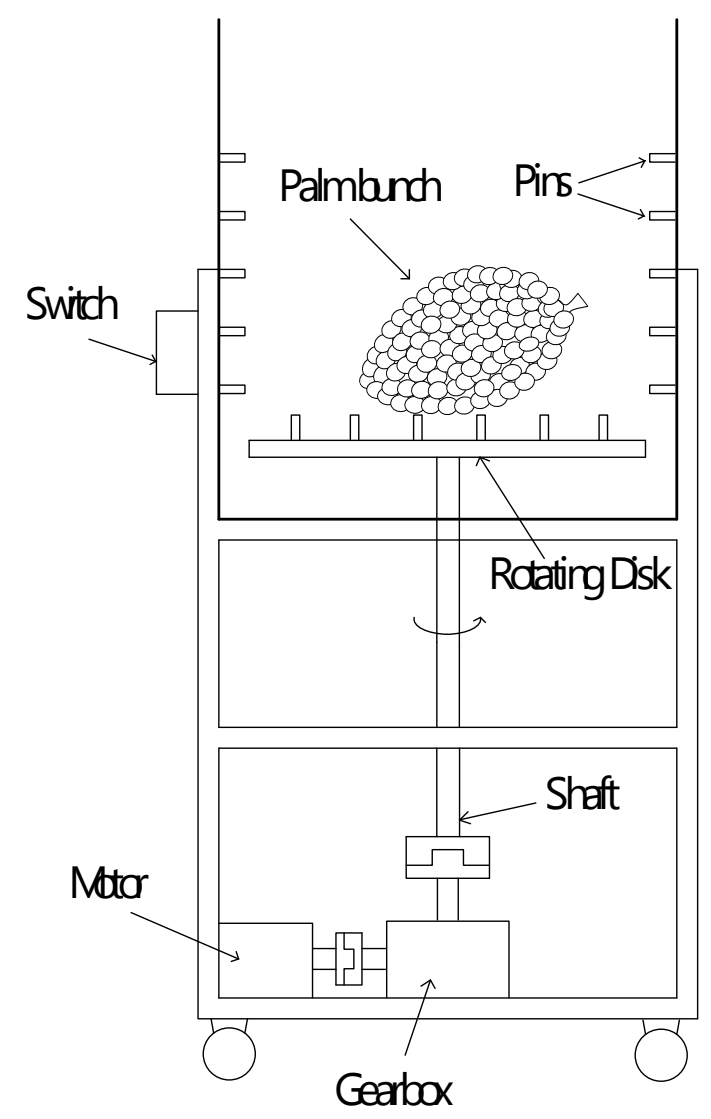

Fig. 2. A schematic diagram of bunch-fruit separator

Percentage of bunch-fruit separation was using following Eq. (1)

$\eta_{M}=\frac{M_{1}-M_{2}}{M_{1}}(100 \%)$

where $\eta_{M}$ was the percentage of bunch-fruit separation by weighing (\%), $M_{1}$ was the total weight of palm fruit bunch $(\mathrm{Kg}), M_{2}$ was the weight of palm fruit bunch including palm fruits which can't be separated from the bunches (Kg).

\subsection{Yield and Quality of Crude Palm Oil}

The palm fruits after separating from bunch were extracted by using screw extraction machine. This machine can extract palm oil from mesocarp without breaking palm shell. This means that kernel crude palm oil was not extracted in this process. The capacity of production was $300-500 \mathrm{~kg} / \mathrm{h}$ of palm fruits driving by $10-\mathrm{HP}$ electric motor. In the process, the sterilized palm fruits were pressed by screw press. Crude palm oil was extracted through the small holes of screw cylinder, and shells with kernel including palm cake (Fiber of mesocarp) were delivered at the exit. The crude palm oil was weighed to evaluate the yield.

Percentage yield of crude palm oil compared to total weight of FFB was determined using following Eq. (2)

$\eta_{m}=\frac{m_{1}}{m_{2}}(100 \%)$ 
where $\eta_{m}=$ Percentage yield of crude palm oil (\%), $m_{1}=$ the weight of crude palm oil $(\mathrm{g}), m_{2}=$ total weight of FFB (g)

After obtaining crude palm oil, 5 grams of each sample were titrated to evaluate FFA by three replications. Chemical used in this titration was ethanol, sodium hydroxide and phenolphthalein. The FFA evaluation was determined using following Eq. (2)

$\% F F A=\frac{(S)(0.1)(25.6)}{m}$

where $\% F F A=$ Free Fatty Acid (\%), $S=$ Amount of sodium used $(\mathrm{ml}), m=$ the sample of crude palm oil (g)

\section{Results}

\subsection{Fruit-Bunch separation}

Comparison of Fresh Fruit Bunch (FFB) and the bunches after splitting, which were sterilized at 30, 40 and 60 minutes, is shown in Figure 3. The results show that at 30 minutes, amount of un-split palms were more than split palms, and the un-split palms were bruised and broken. At 45 minutes, the amount of un-split palms was lesser than those at 30 minutes, but the un-split palms were not bruised and broken as compared to the case of 30 minutes. At 60 minutes, there was no un-split palms unless internal small palm fruits which was not split. It can be seen that logger sterilizing time can affect on softening and facilitating the palm fruits which were easier to split the fruits from the bunch.

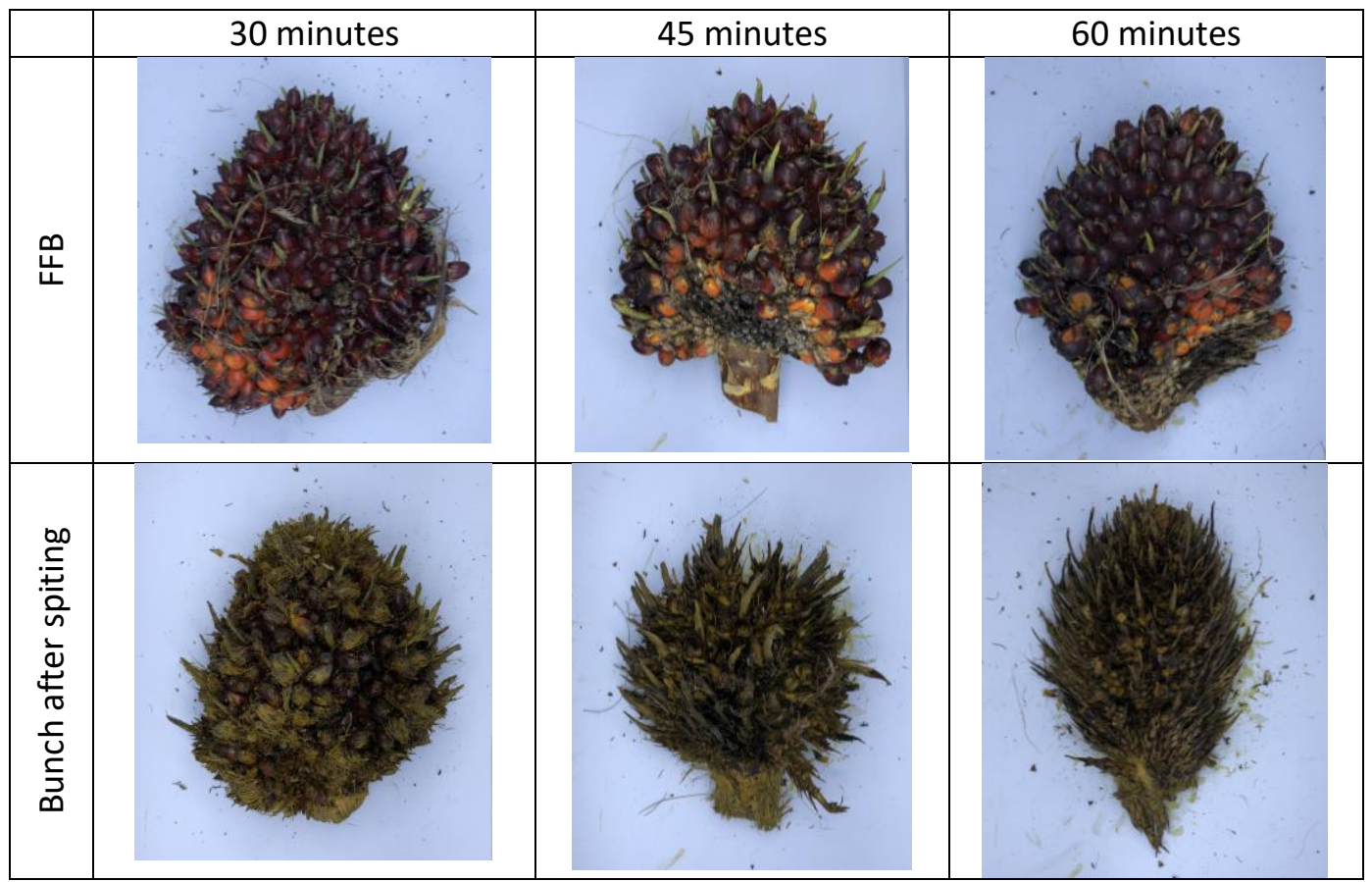

Fig. 3. Comparison of Fresh Fruit Bunch (FFB) and the bunches after splitting

Percentage of fruit-bunch separation of sterilized bunch which was evaluated from eq.(1) is shown in Figure 4 . The results show that at 30 minutes, percentage of fruit-bunch separation was the lowest at $36.89 \%$. However, percentage of fruit-bunch separation was increased up to $86.83 \%$ and 
$90.36 \%$ for 45 and 60 minutes, respectively. This can be concluded that logger sterilizing time can increase fruit-bunch separation.

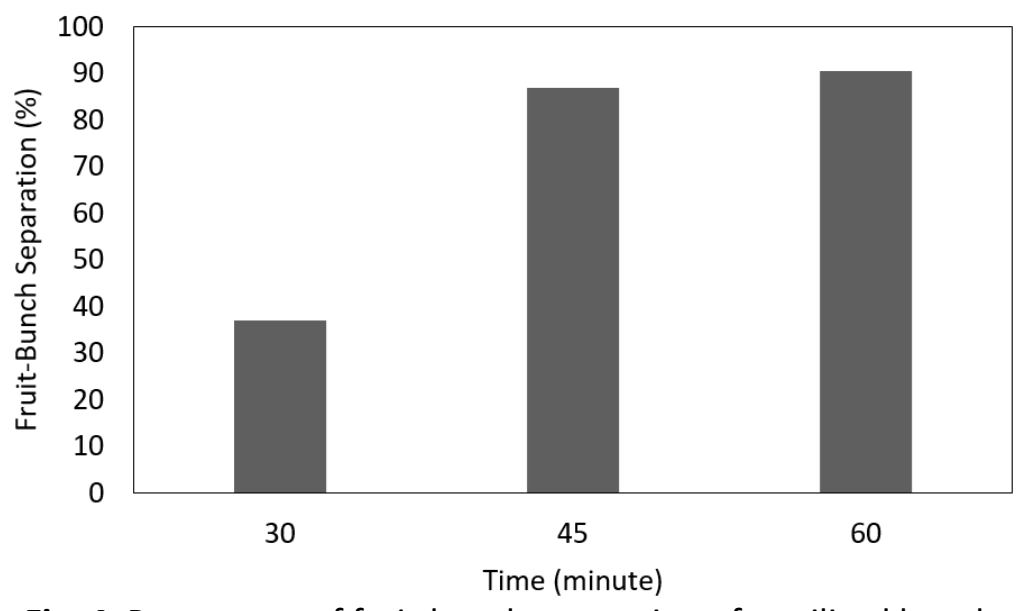

Fig. 4. Percentage of fruit-bunch separation of sterilized bunch

Generally, in large milling factory, the sterilization time is between 45-60 minutes. This time is attributed that it is suitable for separating palm fruits from bunch in crusher machines. In this work, sterilization by direct steaming between 45-60 minutes shown the potential of applying this technique with no degradation in term of splitting the palm fruits from the bunch.

\subsection{CPO Yield}

Percentage yield of crude palm oil which was evaluated from Eq. (2) is shown in Figure 5. The results show that at 30 minutes, the crude palm oil yield was the smallest, $9.86 \%$. At 45 and 60 minutes, the crude palm oil yields were almost the same, $26.57 \%$ and $26.72 \%$, respectively, and were higher than the case of 30 minutes. This corresponds to the percentage of fruit-bunch separation as previously shown in Figure 4 which the percentages of fruit-bunch separation of 45 and 60 minutes were higher than the case of 30 minutes.

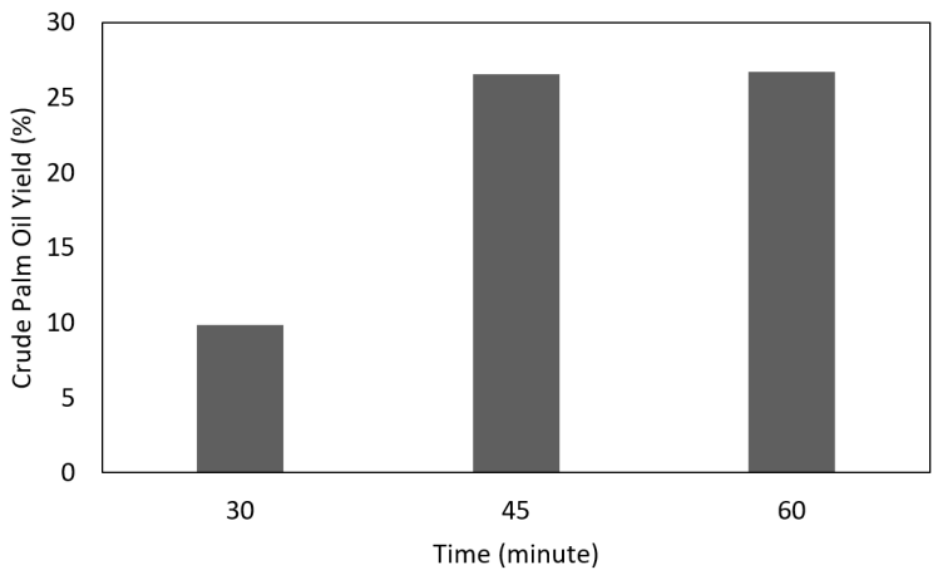

Fig. 5. CPO yield of sterilization palm 


\subsection{CPO quality}

Free fatty acid (FFA) of crude palm oil (CPO) which was evaluated from Eq. (3) is shown in Figure 6. The results show that the FFA was $3.17 \%, 1.2 \%$ and $0.95 \%$ for 30,45 and 60 minutes, respectively. However, all FFAs were less than $5 \%$ which is not exceed than the standard of CPO. This show that a longer sterilization time can affect on minimizing FFA. Low FFA can identify that a quality of CPO is high.

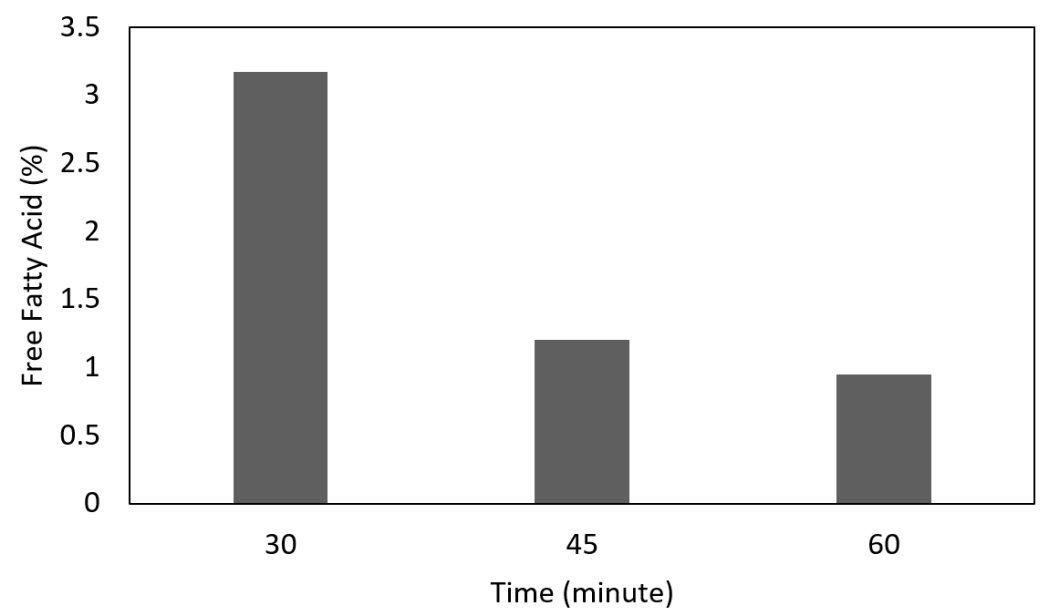

Fig. 4. FFA of CPO extracted from sterilization palm

\section{Conclusions}

In this research, palm fruit bunch was sterilized by direct steaming in mini sterilizer. Sterilization time was varied at 30,45 and 60 minutes while the pressure was fixed at 1.5 bar. The results were concluded as follow:

1. Percentage of fruit-bunch separation and crude palm oil yield increased when sterilization time was longer. The fruit-bunch separation percentage and the oil yield of 30 minutes case is quite different when compared to the case of 45 and 60 minutes. However, the percentages and the yields of 45 and 60 minutes were almost the same level. Sterilization time up to 45 minutes, the bunch can be softened and the palm fruits were facilitated to release from the bunch for undergoing other processes.

2. The trend of increasing crude palm oil yield is similar to the trend of increasing fruit-bunch separation. This indicated that the sterilization time affected directly on softening the bunch which facilitate the fruit release and causing oil to foam which facilitate the oil extraction.

3. Free fatty acid (FFA) of crude palm oil (CPO), which low level indicates high quality of CPO, decreased when sterilization time was longer. This indicated that the sterilization time affected on stopping the enzyme activity in palm oil fruit to avoid the increase of FFA.

Acceding to the results from this work, it is possible to apply this method-combining a boiler and a sterilizer in the same unit for direct steaming-in sterilization process of palm fruit bunch. The pressure and sterilization time used in this work are the same rage which was operated in conventional sterilization process-a method of separating a boiler and a sterilizer. This could be decreased heat losses and waste water from sterilization process. It can be attributed to decrease energy consumption in palm oil sterilization process. 


\section{Acknowledgement}

This work was financially supported by the Research Development Office (RDO) of Prince of Songkla University, Grant No. ENG 6105858.

\section{References}

[1] Badmus G.A., 1991. NIFOR automated small-scale oil palm fruit processing equipment-its need, development and cost effectiveness. Proc. PORIM Int. Palm Oil Conf. Chemistry and Technology, Kualar Lumpur, Malaysia, 20-31.

[2] Nor'aini, S., and W. L. Siew. "Quality control measures in the palm oil industry." Palm Oil Dev (1990).

[3] Oo, Khaik-Cheang, Sau-Keen Teh, Hun-Teik Khor, and Augustine SH Ong. "Fatty acid synthesis in the oil palm (Elaeis guineensis): Incorporation of acetate by tissue slices of the developing fruit." Lipids 20, no. 4 (1985): 205-210. https://doi.org/10.1007/BF02534189

[4] Hudzari, M. Razali, Wan Ishak Wan Ismail, Abd. Rahman Ramli, Md. Nasir Sulaiman, Mohd Haniff Harun. 2010. Colour for Agriculture Product in Al-Quran. Proceeding of 2nd International Conference on Islamic Science and Technology", ISTech 2010,20th-21st Oktober 2010, Johor Bharu, Malaysia. https://doi.org/10.9735/0975-3710.2.2.21-27

[5] Fatin, S. A., S. Rosnah, and R. Yunus. "Effect of chopping oil palm fruit spikelets on the free fatty acid content release rate and its mechanical properties." International Journal of Research in Engineering and Technology 3, no. 1 (2014): 511-516. https://doi.org/10.15623/ijret.2014.0301086

[6] Fatin, S. A., S. Rosnah, and R. Yunus. "Effect of chopping oil palm fruit spikelets on the free fatty acid content release rate and its mechanical properties." International Journal of Research in Engineering and Technology 3, no. 1 (2014): 511-516. https://doi.org/10.15623/ijret.2014.0301086

[7] Zu, A. K. S., S. Adjei-Nsiah, and R. J. Bani. "Effect of processing equipment and duration of storage of palm fruits on palm oil yield and quality in the Kwaebibrem District, Ghana." (2012).

[8] Rajanaidu, N., and B. K. Tan. "Variability of fatty acid composition (FAC) within bunches in the oil palm, Elaeis guineensis." Oleagineux 38, no. 11 (1983): 581-584.

[9] Copeland, D., Belcher, M.W. 2001. Methods for refining vegetable oils and by products thereof. US6172247.

[10] Mangoensoekarjo, S dan H. Semangun. 2003. Manajemen Agrobisnis Kelapa Sawit. Gajah Mada University Press, Yogyakarta.

[11] Kamal Abd. Azis, M. 2003. The study of heat penetration in palm oil fruitlets by developing a new technique for measuring oil content in fruiltlet during sterilization process. Unpublished Paper.

[12] Jusoh, Junaidah Mat, Norizzah Abd Rashid, and Zaliha Omar. "Effect of sterilization process on deterioration of bleachability index (DOBI) of crude palm oil (CPO) extracted from different degree of oil palm ripeness." International Journal of Bioscience, Biochemistry and Bioinformatics 3, no. 4 (2013): 322.

[13] Mahidin, M. R. "Quality improvement in the production of Malaysian palm oil." Palm Oil Development 9 (1998): 15-21.

[14] Sivasothy, K. "Palm oil milling technology." Advances in oil palm research, Vol. 1 (2000): 744-782.

[15] Matthaus, B. 2012. Technological innovations in major world oil crops. Oil technology volume 2: Perspectives https://doi.org/10.1007/978-1-4614-0827-7 2

[16] Let, Chong Chiew. "Handling, storage and transportation of fresh fruit bunch and palm oil products." Palm Oil Technical Bulletin 1 (1995): 2-4.

[17] Olie, J.J., Tjeng, T.D. 1974. The Extraction of Palm Oil. The Incorporated Society of Planters, Kuala Lumpur, pp. 2935.

[18] Hadi, S., D. Ahmad, and F. B. Akande. "Determination of the bruise indexes of oil palm fruits." Journal of food engineering 95, no. 2 (2009): 322-326. https://doi.org/10.1016/i.jfoodeng.2009.05.010

[19] A.A. Hadi, A. W. Mohammad and M. S. Takriff, "Determination of optimum sterilization condition based on calculated heat transfer rate for palm oil mill process", ARPN Journal of Engineering and Applied Sciences, vol. 11, no. 13, 2016.

[20] Malaysian Palm Oil Board (MPOB). 2003. Fresh fruit bunch (FFB) grading manual. Kuala Lumpur: Malaysian Palm Oil Board.

[21] Sukaribin, Nazarulhisyam, and Kaida Khalid. "Effectiveness of sterilisation of oil palm bunch using microwave technology." Industrial Crops and Products 30, no. 2 (2009): 179-183. https://doi.org/10.1016/i.indcrop.2009.05.001 
[22] Umudee, I., M. Chongcheawchamnan, M. Kiatweerasakul, and C. Tongurai. "Sterilization of oil palm fresh fruit using microwave technique." International Journal of Chemical Engineering and Applications 4, no. 3 (2013): 111. https://doi.org/10.7763/IJCEA.2013.V4.274

[23] Han, Ng Mei, Choo Yuen May, and Ma Ah Ngan. "Dry heating of palm fruits: effect on selected parameters." American Journal of Engineering and Applied Sciences 5, no. 2 (2012): 128-131. https://doi.org/10.3844/ajeassp.2012.128.131

[24] Reese, Charles D. Industrial safety and health for infrastructure services. CRC Press, 2008. https://doi.org/10.1201/9781420053814

[25] Kandiah, Sivasothy, Yusof Basiron, A. N. H. A. R. Suki, Ramli Mohd Taha, and Y. H. Tan. "Continuous sterilization: The new paradigm for modernizing palm oil milling." J. Oil Palm Res (2006): 144-152.

[26] Loh, T. W. "Innovative methods in oil processing/oil palm industry." In Proceedings of the 1994 PORIM National Palm Oil Milling and Refining Technology Conference, Kuala Lumpur, pp. 75-80. 1994. 